\title{
MEMÓRIA FEITA DE RETALHOS: SUBJETIVIDADE EM CRISE E VIDA CULTURAL NA BELLE ÉPOQUE
}

\section{CARMEM LÚCIA NEGREIROS DE FIGUEIREDO}

Universidade do Estado do Rio de Janeiro

O artigo apresenta os resultados parciais do estudo e pesquisa sobre Retalhos, do escritor brasileiro Lima Barreto (1881-1922), concentrando-se nas anotações e colagens relativas aos anos de 1900 a 1905. Publicado parcialmente sob o título de Diário íntimo, seu conteúdo foi organizado em sucessão cronológica e linear, diversa da organização originalmente feita pelo escritor. Retalhos é o nome dado por Lima Barreto ao conjunto de recortes e colagens de fragmentos de jornais, observações do cotidiano e folhas de livros versando sobre críticas literárias, mesclados a anotações de ordem pessoal. Nesta leitura do diário feito de 'retalhos', discutem-se aspectos da intensificação da vida moderna e da subjetividade em crise, quer no método de observação e registro, quer na configuração do sujeito que coleciona recortes de jornais para, com eles, narrar a si mesmo. Sugere-se também um pouco do olhar do colecionador que busca reconhecer nas citações, recortes e comentários, um sistema de canalizações subterrâneas das heranças culturais e as redes da memória coletiva. Isto porque Retalhos apresenta simultaneamente o questionamento acerca da subjetividade em crise e um panorama multifacetado de reflexões e acontecimentos que marcaram as primeiras décadas do século XX, na Belle Époque brasileira.

Palavras-chave: Fragmentos. Diário. Crise do sujeito. Memória cultural. Lima Barreto.

\section{ABSTRACT MEMORY MADE OF SCRAPS: CRISIS OF SUBJECTIVITY AND CULTURAL LIFE IN THE BELLE ÉPOQUE}

This paper presents the partial results of the study and research on the work Scraps, by the Brazilian writer Lima Barreto (1881-1922), focusing on the notes and collages relating to the years of 1900 to 1905. Partially published under the title Intimate Diary, its linear chronological succession differs from the author's original organization. Scraps is the name given by Lima Barreto to the set of cutouts and collages of newspapers fragments, everyday life observations and 
book pages covering literary critics, merged with notes of personal order. In this regard of the diary made of 'scraps', aspects of the intensification of modern life and of the subjectivity under crisis are discussed, either through the method of observation and recording, either on the configuration of the subject that collects newspapers cutout to, with them, narrate himself. It also suggests a little bit of the collector's view, who aims to recognize, in the cutouts, quotes and comments, an underground canalizations system of the cultural heritage and the webs of collective memory. This is because Scraps simultaneously presents the questioning about the crisis of subjectivity and a multifaceted panorama of reflections and events which had set the first decades of the twentieth century, during Brazilian Belle Époque.

Keywords: Fragments. Diary. Crisis of the Subject. Cultural Memory. Lima Barreto. CRISIS Y VIDA CULTURAL EN LA BELLE ÉPOQUE

El artículo presenta los resultados parciales de estudio e investigación sobre Retazos, del escritor brasileño Lima Barreto (1881-1922), concentrándose en las anotaciones y colagens relativas a los años de 1900 a 1905. Publicados parcialmente bajo el título de Diario íntimo, su contenido fue organizado en sucesión cronológica y lineal, diferente de la organización originalmente hecha por el escritor. $R e$ tazos es el nombre dado por Lima Barreto al conjunto de recortes y colagens de fragmentos de periódicos, hojas de libros, versando sobre críticas literarias y observaciones del cotidiano, mesclados con anotaciones de orden personal. En esta lectura del diario hecho de 'retazos' se discuten aspectos de la intensificación de la vida moderna y de la subjetividad en crisis, quiere en el método de observación y registro, quiere en la configuración del sujeto que colecciona recortes de periódicos para con ellos, narrarse a sí mismo. Se sugiere también un poco del mirar del coleccionador que busca reconocer en las citaciones, recortes y comentarios, un sistema de canalizaciones subte rráneas de las herencias culturales y las redes de memoria colectiva. Esto porque los Retazos presentan simultáneamente el cuestionamiento acerca de la subjetividad en crisis y un panorama multifacético de reflexiones y acontecimientos que marcaron las primeras décadas del siglo XX, en la Belle Époque brasileña.

Palabras clave: Fragmentos. Diario. Crisis del sujeto. Memória cultural. Lima Barreto. 
Afonso Henriques de Lima Barreto nasceu em 1881, sete anos antes da Abolição da Escravatura no Brasil, e faleceu em 10 de novembro de 1922, meses depois da Semana de Arte Moderna. Escreve nas décadas em que se dá intenso processo de modernização do espaço urbano, com invenções tecnológicas, deslocamentos espaço-temporais e transformações políticas e econômicas que abalaram o cotidiano. Participa desse efervescente momento cultural, atuando na imprensa e em debates com seus contemporâneos, mas, principalmente, inserindo os novos modos de percepção e sensibilidade moderna na estruturação de suas obras.

Retalhos é o nome dado por Lima Barreto ao conjunto de recortes e colagens de fragmentos de jornais, folhas de livros, versando sobre críticas literárias e observações do cotidiano, mesclados a anotações de ordem pessoal. Publicado pela primeira vez em 1953, com o título de Diário Íntimo: memórias, e, em 1956, na edição das obras completas do escritor, com prefácio de Gilberto Freyre, a obra não se apresenta como espaço de registros da intimidade somente e, no dizer do próprio escritor, tem a forma de um "diário extravagante".

Ao organizá-lo para publicação, o biógrafo de Lima Barreto, Francisco de Assis Barbosa, dá ao Diário uma forma e perfil que prendem a sua especificidade a uma concepção trivial do tempo, como cronologia linear, coerente à ideia de continuidade temporal infinita e regular, como se a sucessão cronológica correspondesse à organização e às escolhas originalmente feitas pelo escritor. Na edição de 1956, Francisco de Assis Barbosa informa que o Diário Íntimo aparece "sensivelmente aumentado no seu conteúdo", isso porque, segundo o autor, "entendemos de juntar, às anotações de vida íntima e notas de leitura, os esquemas de romances frustrados, primeiras tentativas de ficcionista, ainda em plena juventude, seguidos às vezes de capítulos inteiros, ao lado de outros apenas esboçados" (BARBOSA, 1956, p. 20).

Estabelece, portanto, o desenho da memória do escritor através da junção de diversos cadernos e cadernetas de anotações e folhas avulsas, mas coerente aos princípios do historicismo, numa representação linear e sequencial da matéria. Para tanto, foram adotados critérios de continuidade temporal, assinalados pelas datas, registradas algumas pelo escritor e outras, em sua maioria, pelas referências de recortes de jornais e revistas que acompanham essas anotações. Trata-se de uma organização pretensamente desinteressada e científica, de um registro que se pode chamar de memória material, feita de fragmentos.

Entre os fragmentos do intitulado Diário Íntimo, que estão na Seção de Manuscritos da Biblioteca Nacional, encontram-se cadernos, completos, sem folhas arrancadas, que reúnem anotações pessoais, associadas aos retaIhos ou recortes de jornais colados nas folhas dos cadernos, acompanhadas das referências do local da publicação, data e título do periódico.

São muitos os registros, de cartas a crônicas, nos quais o escritor Lima Barreto se apresenta como um colecionador de retalhos. "Tenho retalhos de jornais franceses que cortei há anos para me documentar", afirma em uma das suas crônicas do volume Feiras e Mafuás (LIMA BARRETO, 1956a, p. 193). Afinal, argumenta o escritor, em Vida Urbana, "quando queremos ler um jornal com cuidado, fazemos descobertas portentosas" (LIMA BARRETO, 1956b, p. 207). Além da coleção, que reunia em cadernos, com o título de Retalhos, o escritor ainda recebia outros mais de presente, de pessoas próximas conhecedoras de seu interesse por recortes de jornais.

Há meses, um bom velho de minha vizinhança, apaixonado pela leitura de jornais deu-me uma porção de retalhos de vários jornais e de épo- 
cas diversas. Entre eles havia muitos folhetins do Jornal [Jornal do Commercio] que contavam quarenta anos ou mais. (LIMA BARRETO, 1956b, p. 151)

Um exemplo mais direto da correlação entre a coleção de retalhos e a obra do escritor está na constituição do volume de crônicas, denominado pelo escritor de Marginália, e, ao final da primeira crônica - que trata da questão dos poveiros (pescadores portugueses, de Póvoa do Varzim, que exerciam o monopólio da pesca em alto-mar, sem se naturalizarem brasileiros), com dura crítica ao nacionalismo -, explica o seu método de investigação e análise dos temas de que serão feitas as crônicas apresentadas no volume.

Era tal a falta de uma segura orientação nos que se digladiavam, que só tive um remédio para estudá-la mais tarde: cortar as notícias de jornais, colar os retalhos num caderno e anotar à margem as reflexões que esta e aquela passagem me sugerissem. Organizei assim uma 'marginália' a esses artigos e notícias. Uma parte vai aqui. (LIMA BARRETO, 1956c, p. 32)

Apesar da insistência do escritor em expor o método de observação e leitura do mundo, pelo fragmento, pela seleção, pesquisa e um tipo de "arquivamento" peculiar, a crítica enxergou no título do volume de crônicas uma síntese da opção pela retórica que representa a "marginália", a dos empobrecidos e marginais do contexto social. Seu método promove uma produtiva desordem nos acontecimentos porque reúne objetos de espaços e tempos descontínuos, recorta conjuntos compreensiveis, aproxima as lembranças, quando recorda, por afinidades independentes de uma relação causal. O confronto entre a história dos sujeitos, nos jornais mesclados a recortes também de livros, e os relatos oficiais constituem uma privilegiada oportunidade para o escritor (e ao leitor dos Retalhos) repensar paradigmas da interpretação histórica e, a partir de outras formulações e outras experiências, possibilita, também, a emergência de novos sujeitos. Não se trata, pois, de incluir uma narrativa sobre um tema, dentro da narrativa histórica já elaborada, mas da inserção de diferentes agentes, igualmente participantes do processo histórico, que pouco foram ouvidos e considerados, sugerindo uma reescrita de aspectos da história a partir de retalhos.

Tomando por base tais constatações, a proposta da pesquisa sobre os Retalhos, de Lima Barreto, consiste em traçar roteiros possiveis de leitura, entre os fragmentos, em conexão com as diferentes obras do autor, considerando: a) a relação entre a crise da subjetividade e novos modos de percepção e sensibilidade das primeiras décadas do século XX; b) as tensões da vida literária; c) a relação entre imprensa e literatura; d) esboços de obras contidos no diário e o diálogo com as obras publicadas.

Da pesquisa em andamento, apresentamos, neste artigo, somente alguns tópicos dessa fase parcial de estudos, considerando dois aspectos que marcam o período de sua produção: a crise da subjetividade e a intensificação da vida urbana. Ambos iluminam o olhar para a constituição do caderno Retalhos, além do mero registro cotidiano do diário de um escritor.

\section{Crise da subjetividade}

O questionamento acerca da subjetividade e da autonomia da consciência realiza-se sob muitas perspectivas e, desde a primeira metade do século XIX, muitos fatores contribuíram para tornar o indivíduo, simultaneamente, objeto de investigação e produtor de conhecimento. O conjunto de estudos permite delinear um novo perfil de observador e de identidade, tão instáveis e móveis quanto a visão e as sensações. "A visão é redefinida como capacidade de ser afetado por sensações que 
não têm ligação necessária com um referente" (CRARY, 2012, p. 93). Todos esses aspectos vinculam-se à compreensão da modernidade como um registro de experiência subjetiva "caracterizada por choques físicos e perceptivos" (SINGER, 2004, p. 95), em um desdobramento da concepção socioeconômica.

Considero, aqui, o aspecto da modernidade estudada por pensadores como Walter Benjamin (1987), Georg Simmel (2009) e Siegfried Kracauer (2009), que a compreendem a partir da concepção neurológica. Isso porque a vida urbana moderna foi bombardeada por choques fisicos e perceptivos. As mudanças tecnológicas e econômicas atingiram profundamente a estrutura da experiência subjetiva, alterando-lhe as bases fisiológicas e psicológicas, com estímulos sensoriais frequentes e intensos, no caótico, fragmentado e desfamiliarizado espaço da cidade. 0 fundamento psicológico sobre o qual se baseiam as particularidades das grandes cidades é, na expressão de Simmel, "a intensificação da vida nervosa que brota da mudança acelerada e ininterrupta das impressões interiores e exteriores" (SIMMEL, 2009, p. 80). Entre as consequências da exposição da sensibilidade aos constantes estímulos, Simmel aponta a atitude blasé ou "a incapacidade de reagir aos novos estímulos com uma energia que lhes seja adequada" (SIMMEL, 2009, p. 85).

O sujeito - agente e objeto desses impactos da modernização -, pode ser chamado de "observador de segundo grau", caracterizado pela "incapacidade de deixar de se observar ao mesmo tempo em que observa o mundo", segundo analisa Gumbrecht, em Cascatas de modernidade (1998). Torna-se, por isso, inevitavelmente consciente de seu corpo, como aspecto significativo para o conhecimento, e da importância da posição adotada para observar. O corpo e a posição do observador, aliados à experiência temporal - especialmente num contexto de aceleração e desaceleração no tempo oferecido pelas tecnologias -, abalam as formas de representação. "À medida que o tempo histórico parece ser posto em movimento por tantos impulsos convergentes, não é mais possivel pensar o presente como um intervalo de continuidade" (GUMBRECHT, 1998, p. 16).

A cidade, com suas luzes, surpresas e sustos, vitrines, multidões e veículos, torna o sujeito atento e disperso no aspecto cambiante do meio urbano, com inúmeros estímulos visuais e sensações quase mágicas. A mobilidade do olhar, com indivíduos em constante deslocamento, apreendendo ambiências, diversas e simultâneas, servindo-se de inventos ópticos variados para ampliar a capacidade perceptiva, torna a visão quase um fim em si, de dimensão estética, para ser usufruída sem uma causa, justificativa ou consequência. $O$ viés de temporalidade também redimensiona a percepção, valorizando o instante e o impacto que passa a produzir sobre os sentidos, sem a moldura da explicação racional ou do anteparo da causalidade, da utilidade.

Entre relatos de pesquisas, experimentos, descobertas e a intensificação da vida sensorial, no cotidiano, aflora a noção de sujeito como estrutura composta sobre a qual diferentes técnicas e forças poderiam produzir, ou sugerir, diversas experiências, todas igualmente "realidades". Cada vez mais a ideia da visão subjetiva afirma-se como um processo "em que o sujeito é, simultaneamente, objeto de controle e normalização" (CRARY, 2012, p. 93).

No turbilhão de pesquisas, discursos e práticas culturais da segunda metade do século XIX, Friedrich Nietzsche questiona a possibilidade de considerar a realidade fixa e estável, a partir de leis gerais fundadas no sujeito; ataca a supremacia da consciência e a pretensão, a ela atribuída, de domínio e conhecimento pleno de como as ações humanas são produzidas. 
O filósofo pensa a consciência como a parte de um indivíduo que recebe estímulos e responde a eles, a partir de hábitos e antigas interpretações ou marcas mnêmicas. Procura eliminar a distinção entre físico e psíquico, afirmando que os processos psicológicos teriam base neurofisiológica.

Sob essa perspectiva, o "eu" torna-se "uma sintese conceitual que permite escamotear relações de forças" (MARTON, 2000, p. 140) ou "um efeito de relações de domínio e obediência entre forças" (GIACOIA, 2001, p. 69). Nietzsche realiza a destruição da unidade do 'eu', fundada na unidade da consciência e induzida pela função gramatical do sujeito.

É essencial que não nos enganemos a respeito do papel da 'consciência': Ela é a nossa relação com o 'mundo exterior' que ela desenvolveu. Por outro lado, a direção, respectivamente o resguardo e a cautela com respeito ao jogo conjunto das funções corporais, não nos vem à consciência; [...] Em suma: aquilo que se torna consciente está sob relações causais que nos são inacessíveis - a sequência de pensamentos, sentimentos, ideias na consciência não exprime nada a respeito do fato de que essa sequência é uma sequência causal: mas, aparentemente, em grau superlativo é assim. Sobre essa aparência fundamos todas as nossas representações de espírito, razão, lógica etc. [...] Habitualmente, toma-se a consciência mesma como sensorium geral e instância superior: todavia, ela é apenas um meio de comunicação: ela desenvolveu-se nas relações e com respeito a interesse de relações... 'Relações' são aqui entendidas também como as impressões do mundo externo e, de nossa parte, as reações necessárias no caso; da mesma maneira como são aqui entendidos os nossos efeitos no exterior. A consciência não é a condutora, mas um órgão de condução. (NIETZSCHE, 2008, p. 275, grifos do autor)

A consciência, pois, apoia-se sobre um conjunto de forças, cuja completude e complexidade ela não domina e até desconhece. Para Nietzsche, o conceito sintético "eu" reúne uma pluralidade de vivências e estados psí- quicos em uma unidade aparente, criada pela consciência, compreendida como um órgão de condução entre as impressões do mundo externo e as reações necessárias aos estímulos e impressões recebidos. O "eu" é produto da conscientização daquele efeito de comando e disposição anímica sobre os quais se funda a convicção, ou crença, de possuir domínio sobre si, como causa para todo fazer.

Nosso mau costume de tomar como essência um símbolo da memória, uma forma abreviada, e, finalmente, tomá-lo como causa [...] Estabelecer uma espécie de perspectiva no ver, por sua vez, como causa do próprio ver: esse foi o passe de mágica na invenção do 'sujeito', do 'eu'. (NIETZSCHE, 2008, p. 284, grifos do autor)

Para o filósofo, o sujeito é assim compreendido como multiplicidade de forças e relações ou, em suas palavras: "Minha hipótese: o sujeito como multiplicidade" (NIETZSCHE, 2008, p. 263).

A crítica à subjetividade e ao privilégio da consciência constitui um processo de confluência entre os resultados de pesquisas e experimentos sobre a visão, a intensificação da exigência sensorial na realidade urbana, as reflexões sobre o sujeito na filosofia. Nesta, não há uma negação da subjetividade, mas sua projeção em novo lugar,

[...] não mais como constituidora do conhecimento e da ação para tornar-se algo constituído em esferas que não estão ao seu alcance (o inconsciente em Freud, a práxis histórica em Marx e a vontade de poder em Nietzsche). Freud, Nietzsche e Marx revelam [...] a 'realidade' como construção imaginária da consciência (CHAUÍ, 1976, p. 30, grifo da autora).

Leitor contumaz de Nietzsche ${ }^{1}$ e atualizado com as publicações europeias contendo estudos da psicologia clássica, Afonso Henriques de Lima Barreto registra em seus cadernos de anotações, Retalhos, e, no Diário íntimo, obser-

1 Há inúmeras referências diretas ao diálogo intenso de Lima Barreto com Nietzsche, presentes em crônicas, contos, e diários. 
vações da leitura de outros pensadores, como a obra de Jules Gaultier sobre o bovarismo, publicada em 1902, na mesma proporção em que há muitas referências rápidas a autores como Maudsley, o próprio Taine e seu sucessor Ribot, psicólogo, que publicara Essai sur l'imagination créatrice, entre muitos outros.

\section{Belle Époque e vida urbana: "O Rio civiliza-se"}

Nas primeiras décadas do século XX, palavras como ordem e progresso fundamentaram 0 braço autoritário da modernização brasileira. A expressão "O Rio civiliza-se", mote das reformas de Pereira Passos, constituiu poderosa rede de poder na intersecção de discursos médico-cientificistas e proposições político-filosóficas, na incipiente mídia, para a construção do sujeito moderno "catita, elegante, branco" na expressão satírica do autor (LIMA BARRETO, 1990, p. 101).

Um projeto político e estético marcou, portanto, a modernização da cidade do Rio de Janeiro, com base na racionalização do crescimento da cidade e em violenta luta contra o passado cultural, expressa quer na derrubada de prédios e paredes antigas, quer no controle e estetização de hábitos e atitudes da população. No entanto, as paredes "cuja argamassa remonta aos tempos da colônia alojam homens que moram, trabalham, especulam, divertem-se; enfim, que mantêm entre si uma trama complexa de relações sociais (BENCHIMOL, 1992, p. 209). Como consequência, a velha estrutura física da cidade é derrubada e destruída, mas a trama social que nela tinha seu apoio e sustentação não desaparece. Para o escritor Lima Barreto, "não se pode compreender uma cidade sem esses marcos de sua vida anterior, sem esses anais ${ }^{2}$ de pedra que contam

2 Entre "os anais de pedra", estão as ruínas do Convento da Ajuda, cujo desaparecimento o escritor lamenta. 0 convento situava-se onde é hoje a praça da Cinelândia, centro do Rio de Janeiro, e foi demolido em 1911, a sua história" (LIMA BARRETO, 1956d, p. 85).

O símbolo de todo o conjunto de melhoramentos urbanísticos é o projeto da Avenida Central, para atender às novas exigências do tráfego urbano, à necessidade de exposição das novidades tecnológicas, com a iluminação elétrica, os cinematógrafos, as fachadas de vidro e mármore e a circulação de pessoas e mercadorias. 0 espaço da Avenida permite aos transeuntes usufruir a sensação de civilização, progresso e vivência de um futuro sofisticado, em meio ao desfile de produtos importados que saltam dos cartazes publicitários, e vitrines, para a exposição nos corpos dos indivíduos que encenam, nos gestos, vestuários e atitudes, o perfil do consumidor moderno.

A nossa leitura dos Retalhos busca identificar aspectos da sensibilidade moderna e de subjetividade em crise, quer no método de observação e registro, quer na configuração do sujeito que lembra ou coleciona recortes de jornais para, com eles, narrar a si mesmo.

\section{Os Retalhos: panorama e memória individual}

Da complexidade dos cadernos Retalhos, selecionamos para discussão, neste trabalho (resultado ainda parcial de pesquisas), somente as entradas correspondentes aos anos de 1900, 1903, 1904 e 1905.

Desse material, o biógrafo fez a organização do que denominou Diário Íntimo, publicado apenas em 1953, reunindo anotações de 1900 a 1921, um ano antes do falecimento do escritor.

Interessa-nos, portanto, seguir os passos dessa organização para desconstruir a forma publicada, e buscar descobrir os fragmentos diversos e díspares, de notas e colagens, feitas pelo autor. A finalidade desse processo con-

como parte da reforma urbanística. Primeiro convento feminino do Rio, desempenhava importante papel na vida cultural carioca. 
siste em compreender, de um lado, o método dessa peculiar escrita de si, baseada na montagem de fragmentos de recortes de jornais mesclados a anotações pessoais, esboços de obras, citações de leituras feitas etc. De outro, associar tal processo de montagem ao método de criação literária de Lima Barreto, a partir da relação entre os fragmentos do caderno Retalhos e as obras do autor.

Na edição feita pelo biógrafo, o diário abrese com o relato do início do ano letivo na Escola Politécnica, Rio de Janeiro, na data de 02 de julho de 1900. A entrada acompanha-se da epígrafe "Quando comecei a escrever este, uma 'esperança'3 pousou” (LIMA BARRETO, 1956b, p. 27). O primeiro longo parágrafo apresenta um instantâneo de uma cena urbana: o movimento apressado de transeuntes no Largo de São Francisco, centro do Rio de Janeiro, sob um sol escaldante. 0 trecho apresenta o que seria um possivel fragmento de romance e chama a atenção por já conter elementos estéticos, predominantes nas obras ficcionais do escritor, a serem publicadas a partir de 1907.

Assim, nos romances de Lima Barreto, o Rio de Janeiro aparece com traços, cores e movimentos que conduzem o leitor além da superficie. Neles, a visão se torna quase um fim em si mesma, tornando-se fundamental na apresentação de trama e personagens, com a valorização do instante na apreensão de ambiências diversas e simultâneas. Há, ainda, a percepção de que a cidade com seu brilho, fascínio e riscos produz nos sujeitos um misto de êxtase e tédio. Isso porque a experiência urbana oferece a sensação de liberdade e êxtase, embriaguez e vertigem, em uma atmosfera cambiante de sensações, com transgressão de limites espaço-temporais no deslocamento do sujeito pelas ruas.

3 A palavra "esperança" usada no trecho citado não se refere a expectativa ou espera, mas a um tipo de gafanhoto que, na crença popular, sugere boas perspectivas.
A inserção de aspectos impressionistas nos textos ficcionais coaduna-se com o aprofundamento da perspectiva psicológica. A relativização da perspectiva temporal, por meio da justaposição de tempos distintos e do relato de tudo a partir da consciência do protagonista, permite menor valorização da cronologia e dos acontecimentos externos. 0 mais importante é o resultado do tempo e das ações exteriores sobre a personalidade do sujeito. Assim, os efeitos da cor, textura e a valorização da luz garantem dinamismo e evocam a atmosfera pictórica de sensações, ao lado de perambulações, encontros fortuitos, prazeres passivos, sensações inesperadas que, no conjunto, caracterizam a forte nuança impressionista no romance. E o mais importante "a natureza visível, em suas interações instáveis, é uma metáfora grandiosa do instável e ilimitado no sentimento e pensamento do eu inconstante (SHAPIRO, 2002, p. 307).

A antipatia do Largo de São Francisco fica mais acentuada nas primeiras horas da manhã, dos dias de verão. 0 sol o cobre inteiramente e se espadana por ele todo com a violência de um flagelo. Pelo ar, a poeira forma uma película vitrea que fulgura ao olhar, e do solo, com o revérbero, sobe um bafio de forja que oprime os transeuntes. Não há por toda a praça uma nesga de sombra, e as pessoas que saltam dos bondes, caminham apressadamente para a doçura amiga da Rua do Ouvidor. Vão angustiadas e opressas, parecendo tangidas por ocultos carrascos impiedosos. Os negros chapéus-de sóis dos homens e as pintalgadas sombrinhas das senhoras, ao balanço da marcha, sobem e descem como se flutuassem ao sabor das ondulações de um curso d’água. São como flores, grandes flores, nenúfares e ninféias, estranhas e caprichosas, que recurvassem as imensas pétalas ao sol causticante das nove horas da manhã. [...] Os tílburis em fileira ao centro da praça rebrilham como ágatas e as suas pilecas, a aquele calor, dormem resignadamente. (LIMA BARRETO, 1956e, p. 27-28) 
A seguir, na mesma entrada do diário, o texto expande-se para as conversas entre os jovens estudantes da Escola Politécnica e após uma interrupção breve, termina com comentários críticos sobre a teoria positivista em voga na época e o diálogo entre os personagens sobre a maneira de se levar e compreender a vida considerada "como uma escalada de titãs" (LIMA BARRETO, 1956e, p. 27-28).

Em nota de rodapé, o biógrafo e organizador do diário esclarece que o trecho de abertura deve tratar-se de uma das primeiras tentativas de Lima Barreto para escrever um romance. Para o leitor contemporâneo, fica patente que o diário registra a memória do ficcionista e é também a exposição fragmentária de um método de trabalho. Nele estão presentes anotações de ideias e temas para escrever, etapas e inventário da construção de personagens, citações de obras lidas, exercícios estéticos de linguagem como demonstra o belo trecho de inspiração impressionista, acima citado e que abre o diário.

A próxima entrada reúne o conjunto de escritos do ano de 1903 e mostra o teor fragmentário, como uma montagem, do diário de Lima Barreto. Segundo a nota que acompanha o texto, os registros foram extraídos "de uma caderneta com capa de couro negro, com os seguintes dizeres em letras douradas: Agenda Trimestriel 1903" (LIMA BARRETO, 1956e, p. 38). Nas anotações, o princípio do diário como método torna-se cada vez mais evidente: há uma pequena extensão de anotações pessoais, mescladas a uma enumeração de itens do orçamento familiar e relato das dificuldades financeiras da família. Neles, Lima Barreto define sua casa como "um mosaico tétrico de dor e de tolice" (LIMA BARRETO, 1956e, p. 41), pela carência material, de estudo e formação intelectual dos seus membros. A maioria dos registros referem-se a anotações de estudos e leituras feitas, aspectos e curiosidades da vida literária, além de um esboço do romance Clara dos Anjos (romance com mais versões feitas pelo autor e o último a ser publicado). Entre as notas de leituras feitas, encontram-se citações de Shakespeare, Flaubert, George Sand, entre outros, tudo reunido na frase solta, como um fragmento, no diário: "No curso da vida e das leituras" (LIMA BARRETO, 1956e, p. 43).

A entrada seguinte do diário a considerar aqui será a do ano de 1905, na qual se observa a exposição, pelo escritor, do seu método de colecionador e a colagem dos recortes de jornais nos cadernos com o aspecto de "baralhado, como a vida" (LIMA BARRETO, 1956e, p. 71).

Hoje, dia de ano-bom (10. de janeiro de 1905) levantei-me como habitualmente às sete e meia para as oito horas. Fiz a única ablução do meu asseio, tomei café, fumei um cigarro e li os jornais. Acabando de lê-los, arrumei as paredes do meu quarto. Preguei aqui e ali, alguns retratos e figuras, e ele tomou um aspecto mais garrido. Há, de mistura com caricaturas do Rire e do Simplicíssimus, retratos de artistas e generais. Não faz mal; nesse aspecto baralhado, ele terá o aspecto da vida ou da letra " $A$ " do dicionário biográfico, que traz Alexandre, herói de alto coturno, e um Antonio qualquer, célebre por ter inventado certa pomada.

\section{[...] 17 de janeiro}

Desde domingo não tomo notas. Hoje, 17, vou recapitular estes três dias. Domingo, passei-o em casa. Cortando artigos do Figaro do ano passado e os pregando sobre a lídima prosa do nosso Rui Barbosa. Enchi o dia assim e enchi-o agradavelmente, suavemente. (LIMA BARRETO, 1956e, p. 71 e p. 86 )

Observa-se das paredes do quarto às foIhas do diário a prática da seleção de recortes de jornais para colecionar. Os registros do ano 1905 trazem colagens de notícias sobre as precárias condições de trabalho dos criados domésticos, ainda próximas do trabalho escravo; reprodução de textos das cartas de galanteador e assassino de mulheres, publicada nos 
jornais. Tudo mesclado a anotações de leituras feitas, esboços de obras, observações sobre a vida literária, registros do estudo acerca da teoria de Jules Gualtier sobre o bovarismo.

Se, para falarmos com Blanchot (2005), um diário íntimo é "tão livre de forma, capaz de todas as liberdades [...] já que tudo lhe convém, na ordem e desordem que se quer", mas "deve respeitar o calendário" (2005, p. 270), como fica o diário de Lima Barreto, cuja datação foi parcialmente produzida pelo escritor e parcialmente criada pelo biógrafo, a partir das datas de recortes de jornais colados nos cadernos? Vale ressaltar que nem sempre coincidem as datas das notícias recortadas e a data da colagem dos mesmos no caderno, tampouco coincidem a colagem e as datas das anotações manuscritas que as acompanham.

Apesar da suspeita sobre a datação precisa, os fragmentos articulam-se entre si e deixam rastros da vida cultural e literária, dos impasses da literatura frente ao mercado e mídia incipientes, sobre as dificuldades para publicação e divulgação de obras, a atuação da crítica e, sobretudo, o dia a dia de personagens anônimos que deixam rastros nas notícias das seções policiais, de moda e folhetins, e da vida urbana.

\section{0 de julho (1905)}

Campo de Sant'Anna. Uma mulher me veio ao banco em que eu estava sentado, trazendo uma criança no colo e pediu-me algum dinheiro. Dei-lhe trezentos réis. Rico Brasil! Não há miséria. Disse-me ela que a criança não tinha mãe, mas eu creio que quem lhe faltava era o pai. (LIMA BARRETO, 1956e, p. 104)

No mesmo contexto de reformas urbanas, de modernização dos meios de comunicação e transporte, entra no país a moda científica, pela literatura: modelos e teorias ganhavam larga divulgação por meio dos heróis, e dos enredos, que privilegiavam as máximas científicas evolucionistas. Ainda que não formassem um grupo homogêneo, esses intelectuais guardavam certa afinidade que os unia: circulavam pelos diferentes centros, estabelecendo relações de intercâmbio cultural, por um lado e, por outro, garantiam, com isso, certo reconhecimento e polivalência para encobrir a parca especialização e a frágil delimitação das áreas de saber (SCHWARCZ, 1993).

Entraram no Brasil, a partir de 1870 , teorias como positivismo, darwinismo, evolucionismo, coerentes ao projeto de naturalização das diferenças, alimentado pelo imperialismo europeu. Ora, a ciência localiza-se num campo de saber e nele tem um papel, que varia conforme as diferentes formações discursivas, isto é, a ciência se inscreve e funciona no elemento do saber e é nesse espaço de ação que se intensificam as relações da ideologia com as ciências, como já nos mostrou Foucault:

A questão da ideologia proposta à ciência não é a questão das situações ou das práticas que ela reflete de um modo mais ou menos consciente; não é a questão de sua utilização eventual ou de todos os empregos abusivos que se possa dela fazer; é a questão de sua existência como prática discursiva e de seu funcionamento entre outras práticas. (FOUCAULT, 2002, p. 210)

Nas realizações de artigos e documentos, nas práticas de biografias de intelectuais, em discursos, nas revistas dos institutos de cultura, e pesquisas histórico-geográficas, disciplinas como antropologia e etnologia assumem importância crescente. As teorias raciais apresentavam-se como modelo teórico viável no complicado jogo de interesses políticos, até a primeira metade do século XX e, por isso, transformaram-se em argumentos de sucesso para o estabelecimento das diferenças sociais.

Nesse contexto, aumentam os estudos de antropologia criminal e de direito penal, combinando-se às teorias raciais e aos debates sobre o perfil e destino da nação. A atmosfera cientificista reunia tendências díspares entre 
si - de modelos biológicos e etnográficos a naturalismo evolucionista e positivismo francês -, além de organização de institutos e lugares de saber e espaços de poder, como quartéis, prisões, asilos, hospícios, para enquadrar os sujeitos, controlar os riscos na cidade e desenhar um perfil de brasilidade. Intelectual sensivel às questões de seu tempo, Lima Barreto realiza muitas anotações nas quais manifesta o questionamento sobre a força do saber científico, autoritário, nas primeiras décadas do século XX.

Vai se estendendo pelo mundo a noção de que há umas certas raças superiores e umas outras inferiores, e que essa inferioridade, longe de ser transitória, é eterna e intrínseca à própria estrutura da raça. [...] Tudo isso se diz em nome da ciência e a coberto da autoridade de sábios alemães. [...] 0 que se diz em alemão é verdade transcendente. [...] Urge ver o perigo dessas ideias, para nossa felicidade individual e para a nossa dignidade superior de homens. Atualmente ainda não saíram dos gabinetes e laboratórios, mas, amanhã, espalhar-se-ão, ficarão á mão dos políticos, cairão sobre as rudes cabeças da massa, e talvez, tenhamos que sofrer matanças, afastamentos humilhantes, e os nossos liberalíssimos tempos verão uns novos judeus. (LIMA BARRETO, 1956e, p. 111)

Ainda é "tentador para o escritor manter um diário da obra que está escrevendo?" (BLANCHOT, 2005, p. 276). A ficção do diário teria relação com a obra que o escritor prepara? No caso de Lima Barreto, é muito interessante perceber a estreita vinculação entre o "curso da vida", as leituras e a escrita, entre os procedimentos e exercícios na linguagem, na escolha de personagens (seus nomes, atitudes, perfis) e o cotidiano em meio ao trabalho burocrático, as tensões familiares, os deslocamentos pela cidade.

Deixando a botica, fui à rua do Ouvidor; como estava bonita, semi-agitada! Era como um boulevard de Paris visto em fotografia.
Fui de trem, meditei durante a viagem sobre o meu livro, e em casa compulsei as notas para acabar o terceiro capítulo. Agora acabo de achar uma pequena cena para o segundo, com a qual dar-lhe-ei mais força, mais vida, mais verossimilhança.

Agita-me a vontade de escrever já, mas nessa secretaria de filisteus, em que me debocham por causa da minha pretensão literária, não me animo a fazê-lo.

Fá-lo-ei em casa. (LIMA BARRETO, 1956e, p. 96)

o interessante é o dinamismo que não possibilita ao diário a elaboração da narrativa contínua e linear, produzindo quase que uma escrita imagética por justaposição de recortes, citações, notas pessoais, anotações de estudos e projetos de obras. A justaposição desses elementos produz o efeito de sobreposição temporal, o imbricamento passado-presente, pela acumulação, de forma descontínua, de fatos, notas e registros, em momentos diversos entre si e do momento da colagem dos recortes: as datas das notícias contidas nos jornais não correspondem necessariamente às datas em que foram coladas; as notícias dos jornais, as citações das obras literárias, filosóficas, sociológicas de períodos diversos justapõem-se às anotações do dia a dia do escritor. Nesse processo de montagem, fragmentos isolados são reunidos diferentemente da lógica sequencial e encadeada de uma narrativa. No entanto, tal reunião produz um novo efeito, novos sentidos, exige nova leitura. Afinal, o diário resulta num mosaico de citações e fragmentos diversos, produzindo o deslocamento dos conteúdos temporais e espaciais. A leitura em concomitância desses fragmentos expõe novo sentido e nova forma de falar de si.

A forma do diário, em fragmentos, coaduna-se com as turbulências e a oscilação da noção de subjetividade e das formas da escrita de si. O processo de apresentação do sujeito, no diário, não é fechado, unitário, concluso. Os 
múltiplos recortes e variadas notas sugerem que não existe um espaço e forma privilegiados de representação das próprias vivências, mas a escrita está em processo, tanto quanto o sujeito.

Ao leitor fica também a liberdade, que possui o colecionador, de construir suas próprias regras e sequências, de desfazer-se delas novamente e, diante das seguintes particularidades, realizar alguns questionamentos.

Se um diário é também um recurso contra a solidão, considerando a crise da subjetividade nas primeiras décadas do século XX, o diário de Lima Barreto lança a suspeita sobre a convicção de que podemos nos observar e nos conhecer.

Além disso, como sinalizador do método de criação literária do escritor, o diário permite o traçado de vários roteiros de leitura em conexão com os caminhos possíveis no diálogo com a obra do escritor. Em comparação ao contexto contemporâneo à sua produção, os Retalhos

\section{Referências}

BARBOSA, Francisco de Assis. A vida de Lima Barreto (1881-1922). 6. ed. Rio de Janeiro: J. Olympio; Brasília, DF: INL, 1981.

Nota prévia a Diário Íntimo. In: LIMA BARRETO, Afonso Henriques de. Diário intimo. São Paulo: Brasiliense, 1956. p. 09-21.

Benchimol, Jaime Larry. Pereira Passos: um Haussman tropical: a renovação urbana da cidade do Rio de Janeiro no início do século XX. Rio de Janeiro: Secretaria Municipal de Cultura, Turismo e Esportes/ Departamento Geral de Documentação e Informação Cultural, Divisão de Editoração, 1992.

BENJAMIN, Walter. O narrador. Trad. Sérgio Paulo Rouanet. In: BENJAMIN, Walter. Obras escolhidas I. 3. ed. São Paulo: Brasiliense, 1987a. p. 197-221.

BENJAMIN, Walter. A obra de arte na era de sua reprodutibilidade técnica. Trad. Sérgio Paulo Rouanet. apresentam um panorama multifacetado, com imbricamento de tendências, reflexões e acontecimentos que marcaram as primeiras décadas do século XX, no pensamento, na arte, na cultura.

O Diário Íntimo/Retalhos é, portanto, método e desvio e cabe ao leitor o desafio para encontrar as formas de lê-lo, de estabelecer as várias correlações possiveis com seu texto feito da montagem de fragmentos, sem se perder nas suas curvas e avalanche de citações ou sem se prender em fragmentos isolados. Considerar a justaposição e a simultaneidade auxilia na leitura para integrar e dar movimento aos 'retalhos', desconstruindo a totalidade e ordem aparentes. Ao leitor sugere-se também um pouco do olhar do colecionador que busca reconhecer nas citações, alusões, paráfrases, comentários um sistema de canalizações subterrâneas das heranças culturais que iluminam as escolhas literárias e as redes da memória coletiva.

In: BENJAMIN, Walter. Obras escolhidas I. 3. ed. São Paulo: Brasiliense, 1987b. p.165-196.

BLANCHOT, Maurice. 0 livro por vir. Trad. Leyla Perrone-Moisés. São Paulo: Martins Fontes, 2005.

CHAUÍ, Marilena S. A destruição da subjetividade na filosofia contemporânea. Jornal de Psicanálise, São Paulo, v. 8, n. 20, p. 29-36, 1976.

CRARY, Jonathan. Técnicas do observador. Trad. Verrah Chamma. Rio de Janeiro: Contraponto, 2012.

FOUCAULT, M. A arqueologia do saber. Trad. Luiz Felipe Baeta Neves. 6. ed. Rio de Janeiro: Forense Universitária, 2002.

GUMBRECHT, Hans Ulrich. Cascatas de modernidade. In: GUMBRECHT, Hans Ulrich Modernização dos sentidos. São Paulo: Ed. 34, 1998. p. 9-32.

GIACOIA, Oswaldo. Nietzsche como psicólogo. São 
Leopoldo, RS: Ed. Unisinos, 2001.

KRACAUER, Siegfried. 0 ornamento da massa: ensaios. Trad. Carlos Eduardo Jordão Machado e Marlene Holzhausen. São Paulo: Cosac Naify, 2009.

LIMA BARRETO, Afonso Henriques de. Feiras e Mafuás. São Paulo: Brasiliense, 1956a.

Vida Urbana. São Paulo: Brasiliense, 1956b. Marginália. São Paulo: Brasiliense, 1956c.

Recordações do escrivão Isaías Caminha. São Paulo: Ática, 1990.

Bagatelas. São Paulo: Brasiliense, 1956d.

Diário Íntimo. São Paulo: Brasiliense, $1956 \mathrm{e}$.

MARTON, Scarlett. Nietzsche: consciência e inconsciente. In: MARTON, Scarlett. Extravagâncias: ensaios sobre a filosofia de Nietzsche. ljuí, RS: Unijuí; São Paulo: Discurso Editorial, 2000. p. 167-182.

NIETZSCHE, Friedrich. A vontade de poder. Trad.
Marcos Sinésio P. Fernandes e Francisco José D. de Moraes. Rio de Janeiro: Contraponto, 2008.

SHAPIRO, Meyer. Impressionismo: reflexões e percepções. Trad. Ana Luiza Dantas Borges. São Paulo: Cosac \& Naify, 2002.

SCHWARCZ, L. M. O espetáculo das raças. Cientistas, instituições e questão racial no Brasil - 1870-1930. São Paulo: Companhia das Letras, 1993.

SIMMEL, Georg. As grandes cidades e a vida do espírito. Trad. Artur Morão. In: SIMMEL, Georg. Psicologia do dinheiro e outros ensaios. Lisboa: Texto e Grafia, 2009. p. 79-97.

SINGER, Ben. Modernidade, hiperestímulo e o início do sensacionalismo popular. In: CHARVEY, Leo; SCHWARTZ, Vanessa. (Orgs.). 0 cinema e a invenção da vida moderna. São Paulo: Cosac Naify, 2004. p. 95-123.

Recebido em: 05.05.2016

Aprovado em: 20.07.2016

Carmem Lúcia Negreiros de Figueiredo é Professora Associada da Universidade do Estado do Rio de Janeiro (UERJ). Tem mestrado e doutorado em Teoria da Literatura pela UFRJ. É pesquisadora do CNPq e Procientista UERJ/FAPERJ. Possui artigos e livros publicados sobre o escritor Lima Barreto. Atualmente, tem no prelo (EDUSP) o volume Lima Barreto, caminhos de criação. Coordena o LABELLE - Laboratório de estudos de cultura e literatura da Belle Époque - sediado no Instituto de Letras, UERJ e o Gr. Pesq CNPq também sobre a mesma temática de pesquisa.

E-mail: carmemlucianegreiros@gmail.com

Av. Rui Barbosa, 288, casa, São Francisco. Niterói, RJ Brasil CEP: 24.360-440 